\begin{abstract}
Iranica
Abstracta Iranica Revue bibliographique pour le domaine irano-aryen

Volume 34-35-36 | 2017

Comptes rendus des publications de 2011-2013
\end{abstract}

\title{
Charles Melville (ed.). Persian Historiography
}

\section{Denise Aigle}

\section{(2) OpenEdition \\ Journals}

Édition électronique

URL : http://journals.openedition.org/abstractairanica/41831

DOI : 10.4000/abstractairanica.41831

ISSN : 1961-960X

Éditeur :

CNRS (UMR 7528 Mondes iraniens et indiens), Éditions de l'IFRI

Référence électronique

Denise Aigle, «Charles Melville (ed.). Persian Historiography », Abstracta Iranica [En ligne], Volume 34-35-36 | 2017, document 13, mis en ligne le 30 décembre 2016, consulté le 27 septembre 2020 URL : http://journals.openedition.org/abstractairanica/41831 ; DOI : https://doi.org/10.4000/ abstractairanica. 41831

Ce document a été généré automatiquement le 27 septembre 2020.

Tous droits réservés 


\title{
Charles Melville (ed.). Persian Historiography
}

\author{
Denise Aigle
}

\section{RÉFÉRENCE}

Charles Melville (ed.). Persian Historiography. London, Tauris, 2012, lvi + 725 p., bibliographie, index. ISBN 978-1-845-11911-9 (A History of Persian Literature, vol. X)

1 Persian Historiography, publié sous la direction de Charles Melville, constitue un apport significatif en la matière. Il couvre une très longue période historique (depuis l'émergence d'une tradition historiographique persane au $X^{e} s$. jusqu'à l'époque pahlavie au $\mathrm{XX}^{\mathrm{e}}$ ), tout en incluant les aires culturelles hors de l'Iran où une historiographie en langue persane a été produite (Empire ottoman jusqu'au XVI ${ }^{\mathrm{e}} \mathrm{s}$., Asie centrale depuis le XVI ${ }^{\mathrm{e}} \mathrm{s}$. et Inde musulmane). Cet ouvrage comporte douze chapitres, précédés d'une substantielle introduction (xxv-lvi) rédigée par Charles Melville. Dans le chapitre 1 "History as literature » (p. 1-55), après avoir décrit comment est née la tradition historiographie persane au $\mathrm{X}^{\mathrm{e}} \mathrm{s}$. (p. 6-19), J. Scott Meisami explique que les auteurs médiévaux n'avaient pas l'intention d'écrire des récits fictionnels, mais qu'il s'agissait d'adopter un style narratif destiné à une audience qui avait la capacité de comprendre ce qui peut apparaître aujourd'hui comme de la fiction. Le chapitre 2 « The historian at work » (p. 56-100), rédigé par Charles Melville, est consacré aux historiens en tant qu'acteurs de l'administration, de la politique et de la vie culturelle. Le style « inš $\breve{a}$ ' » des scribes, qui devint dominant, donna naissance à une prose très stylisée, avec l'insertion de fragments de poésie et de citations coraniques (p. 58). Elton L. Daniel, dans le chapitre 3 "The rise and development of Persian historiography " (p. 101-154), revient sur les origines de l'historiographie persane qui s'est développée au moment où l'historiographie arabe entrait dans sa maturité (p. 102). Il explique que la traduction du Ta'rî̀ al-rusul wa-l-mulūk de Ṭabarī par Abū 'Alī Bal'amī n'était pas une fidèle reproduction en persan du texte de Tabarī, mais une vison iranienne de l'histoire des débuts de l'islam. Il faudra attendre un siècle après la composition du TārīH de Bal'amī 
pour que les ouvrages historiques originaux en persan apparaissent. Le chapitre 4 « The Mongol and Timurid periods, 1250-1500 » (p. 155-208) est une réflexion sur la manière dont les historiens ont intégré les conquérants turko-mongols dans l'histoire de l'Iran. À cette époque, l'Iran acquiert une nouvelle place dans le monde musulman qui se manifeste par la revivification du concept « terre d'Iran » (İrān-zaminn). Cette notion est à la fois géographique et politique : elle donne une identité aux conquérants. Dans son Nizām al-tawārīH, Bayḍawī met l'accent sur l'histoire de sa province natale, le Fārs, comme étant le centre du premier empire persan. Il considère que le concept « terre d'Iran " (İān-zamin) recouvre le territoire compris entre l'Euphrate et l'Oxus. Cette chronique est sa seule œuvre rédigée en persan, une manière implicite de relier la langue à l'identité. Le chapitre 5 "Safavid historiography » (p. 209-257) est rédigé conjointement par Sholeh Quinn et Charles Melville. Les œuvres produites aux périodes mongole et timouride ont constitué les bases de l'historiographie safavide. Le Jāmi' altawārīH de Rašīd al-Dīn, les nombreux ouvrages de Ḥâfiza-i Abrū et les histoires universelles de la tradition hératie (le Rawdat al-ṣafā' de MīrH̦̄ānd et le Habỉb al-siyar de $H^{\mathrm{w}}$ āndmīr) servent de pont avec l'historiographie safavide. Dans le chapitre 6 « Persian Historiography in the 18th and early 19th century » (p. 258-291), Ernest Tucker examine les chroniques produites à l'époque des Afshars, des Zands et au début des Qajars. La chute des Safavides a fragmenté l'autorité politique, mais les chroniques royales ont maintenu le même style littéraire que pendant les 150 années précédentes. On note cependant une certaine emphase à accroître l'emploi de la poésie (ce qui avait décliné à la fin de l'époque safavide), notamment du "style indien " (sabk-i hindī) qui était devenu populaire en Iran au XVII ${ }^{e}$ s. (p. 258). Abbas Amanat dans le chapitre 7 « Legend, legitimacy and making a national narrative in the historiography of Qajar Iran (1785-1925)» (p. 292-366) propose une analyse de cette production historiographique qualifiée de " proto-nationaliste ", qui constitue un prologue à l'histoire pahlavie. Les historiens mettent l'accent sur la continuité politique en Iran depuis l'époque préislamique jusqu'aux temps modernes ; ils écrivent dans un " pur " style persan (pārsi-yi sara), un style qui élimine la langue fleurie des chroniques timourides et safavides (p. 327). La présentation par Fakhreddin Azimi de la production historiographique de l'époque pahlavie fait l'objet du chapitre 8 « Historiography in the pahlavi era » (p. 367-435) dans lequel l'auteur ne propose qu'une simple description des textes. Sara Ylldiz dans le chapitre 9 "Ottoman historical wrinting in Persian, 1400-1600 " (p. 436-502) offre un riche tableau sur l'historiographie persane à cette période. La rédaction d'histoires versifiées persanes à l'image du Šāh-nāma a été reprise par les sultans ottomans. Il s'agit de littérature panégyrique et de propagande dynastique dans laquelle l'Empire ottoman est souvent présenté comme l'apogée de l'histoire du monde musulman. Stephen Dale dans « Indo-Persian historiography » (p. 565-610) conclue le volume par une riche discussion sur l'historiographie indo-persane, principalement sous les Moghols.

Dans Persian Historiography, les AA. analysent les textes dans leur contexte historique et leur milieu de production, avec une attention particulière aux buts visés par les historiens, au style utilisé et à la langue. Née en Iran oriental au X ${ }^{\mathrm{e}} \mathrm{s}$., l'historiographie a pu se développer lorsqu'une langue persane a vu le jour et que les œuvres de Țabarī (son Tafsìr et son $\mathrm{Ta}^{\prime} \mathrm{rïH}_{\mathrm{H}}$ ) ont été traduits en persan. Les périodes mongole et timouride (XIII ${ }^{e}$ XIV ${ }^{e}$ s.) ont produit les modèles historiographiques dont ont hérité les historiens postérieurs jusqu'à l'époque qajare. Avec les Qajars, une nouvelle étape fut franchie avec le début d'une historiographie « nationaliste » qui trouvera sa pleine expression 
sous les Pahlavis. L'attachement au passé antique de l'Iran a trouvé son expression dans l'utilisation, par les historiens, du genre littéraire versifié (ou d'extraits) du Šāh-nāma pour rédiger des textes historiques est l'une des caractéristiques de la tradition historiographique en Iran. Il faut également souligner que la plupart des textes historiques sont centrés sur la personne du prince, qu'il soit exalté comme un conquérant, bras armé de l'islam, comme le fut Sultạn Maḥmūd de Ġazna partit conquérir l'Inde, ou encore comme Šāh Ismāâil qui, imposant le chiisme duodécimain comme religion d'État, a donné à l'Iran son identité spécifique au sein du monde musulman. L'histoire partage également un certain nombre de points communs avec la littérature de Miroirs des princes qui, en Iran, a également puisé dans le passé de la Perse antique.

\section{AUTEURS}

\section{DENISE AIGLE}

CNRS-UMR 8167 « Orient et Méditerranée » 